\title{
Heterodyne detection of CPFSK signals with and without wavelength conversion up to
} $5 \mathrm{~Gb} / \mathrm{s}$

\author{
Pedersen, Rune Johan Skullerud; Ebskamp, F.; Mikkelsen, Benny; Durhuus, T.; Öberg, M.; Nilsson, S.
}

Published in:

I E E E Photonics Technology Letters

Link to article, DOI:

$10.1109 / 68.238263$

Publication date:

1993

Document Version

Publisher's PDF, also known as Version of record

Link back to DTU Orbit

Citation (APA):

Pedersen, R. J. S., Ebskamp, F., Mikkelsen, B., Durhuus, T., Öberg, M., \& Nilsson, S. (1993). Heterodyne detection of CPFSK signals with and without wavelength conversion up to $5 \mathrm{~Gb} / \mathrm{s}$. I E E E Photonics Technology Letters, 5(8), 944-946. https://doi.org/10.1109/68.238263

\section{General rights}

Copyright and moral rights for the publications made accessible in the public portal are retained by the authors and/or other copyright owners and it is a condition of accessing publications that users recognise and abide by the legal requirements associated with these rights.

- Users may download and print one copy of any publication from the public portal for the purpose of private study or research.

- You may not further distribute the material or use it for any profit-making activity or commercial gain

- You may freely distribute the URL identifying the publication in the public portal 


\title{
Heterodyne Detection of CPFSK Signals With and Without Wavelength Conversion up to $5 \mathrm{~Gb} / \mathrm{s}$
}

\author{
R. J. S. Pedersen, F. Ebskamp, B. Mikkelsen, T. Durhuus, M. Öberg, and S. Nilsson
}

\begin{abstract}
In this letter we report detection of wavelength converted signals by a coherent CPFSK receiver. The signals are wavelength converted over $35 \mathrm{~nm}$, and we measure record receiver sensitivities of $-38.7 \mathrm{dBm}$ at $4.0 \mathrm{~Gb} / \mathrm{s}$ and $-35.6 \mathrm{dBm}$ at $4.8 \mathrm{~Gb} / \mathrm{s}$. Comparison between results with and without wavelength conversion, relative to theory, results in a small penalty of less than $1.5 \mathrm{~dB}$.
\end{abstract}

\section{INTRODUCTION}

$\mathrm{T}$ HE coherent multichannel (CMC) technique is a promising method for implementation of multichannel frequency division multiplexing (FDM) networks [1]. Heterodyne receivers exhibit both high sensitivity and good selectivity, and they may prove to be advantageous to use in network structures, where large fan-out, narrow channel spacing, and fast channel switching are required. In this context also, high-speed all-optical wavelength converters are key components, since the flexibility and capacity of FDM systems can be greatly enhanced by reuse and reallocation of carrier wavelengths [2].

In this paper we investigate the combination of the two techniques, using the sensitivity and selectivity advantage of the heterodyne receiver and the network flexibility of the wavelength converter. Wavelength conversion of DPSK signals at $140 \mathrm{Mb} / \mathrm{s}$ was reported earlier [3], without bit error rate (BER) measurements. We report the application of a CPFSK heterodyne receiver to detect wavelength converted signals at bit rates of up to 4.8 $\mathrm{Gb} / \mathrm{s}$. Also, we include BER simulations, using an accurate CPFSK system model [4].

We have used a DBR laser as wavelength converter, since it is possible to get an all-optical conversion up to $\mathrm{Gb} / \mathrm{s}$ data rates [5], [6]. The conversion is performed by an incoming AM signal through optical modulation of the carrier density in the gain section of the DBR laser. The use of optical modulation eliminates the influence of electrical parasitics, and the maximum speed of operation

Manuscript received April 22, 1993. This work was supported by the Danish Technical Research Council.

R. J. S. Pedersen, F. Ebskamp, B. Mikkelsen, and T. Durhuus are with the Center for Broadband Telecommunications, Electromagnetics Institute, Technical University of Denmark, DK-2800 Lyngby, Denmark.

M. Öberg and S. Nilsson are with the Swedish Institute of Microelectronics, S-164 21 Kista, Sweden.

IEEE Log Number 9210770 . is determined by the intrinsic characteristics of the DBR laser. The conversion range is given by the gain bandwidth of the DBR laser, and the output wavelength range is given by the tuning range of the DBR laser.

\section{SYSTEM SETUP}

The experimental setup for heterodyne detection of wavelength converted signals is shown in Fig. 1. A threeelectrode $\lambda / 4$-shifted MQW DFB laser [7] is used as a remote CPFSK transmitter. The light is launched into a fiber-based interferometer with a free spectral range (FSR) of $16 \mathrm{GHz}$. Here, the signal is FM/AM converted, resulting in an AM signal with an extinction ratio larger than 10 $\mathrm{dB}$ and negligible chirp. The light is coupled through a fiber coupler into the DBR laser wavelength converter [5], where the AM signal at a wavelength $\lambda_{1}=1548 \mathrm{~nm}$ is converted into a CPFSK signal at a wavelength of $\lambda_{2}=$ $1514 \mathrm{~nm}$. The wavelength conversion range is shown in Fig. 2, where the optical spectrum from the DBR laser at threshold is depicted together with the signal from the remote signal laser. The DBR wavelength is as indicated in the range $1511-1514 \mathrm{~nm}, \sim 35 \mathrm{~nm}$ from the wavelength of the remote signal laser. Output wavelengths of 1514.1 and $1512.5 \mathrm{~nm}$ have previously been used from this DBR laser [5].

The FM response of the optically modulated DBR laser is very important for a high-quality CPFSK output signal. The relative FM response is presented in Fig. 3 with the current in the gain section as a parameter. At a gain current of $100 \mathrm{~mA}$, a flat FM response is obtained with a bandwidth of $3.3 \mathrm{GHz}$.

The output signal from the wavelength converter is fed through an optical attenuator and into the coherent receiver. The coherent receiver uses a balanced low-noise tuned front end [8], with an average noise spectral density of $16.9 \mathrm{pA} / \sqrt{\mathrm{Hz}}$ and a common-mode-rejection ratio of more than $26 \mathrm{~dB}$. The intermediate frequency (IF) is 10.3 $\mathrm{GHz}$, and the IF band is from 6.4 to $14.2 \mathrm{GHz}$. A DBR laser, matched to the wavelength converter, is used as a local oscillator (LO), and it generates a total photocurrent of $1.1 \mathrm{~mA}$. The IF system linewidth is measured to be 20 $\mathrm{MHz}$. To match the delay in the demodulator, a frequency deviation of $3.2 \mathrm{GHz}$ is required. Modulating the remote signal laser with a bit rate of $3.2 \mathrm{~Gb} / \mathrm{s}$, the obtained IF spectrum shown in Fig. 4(a) indicates a modulation index 


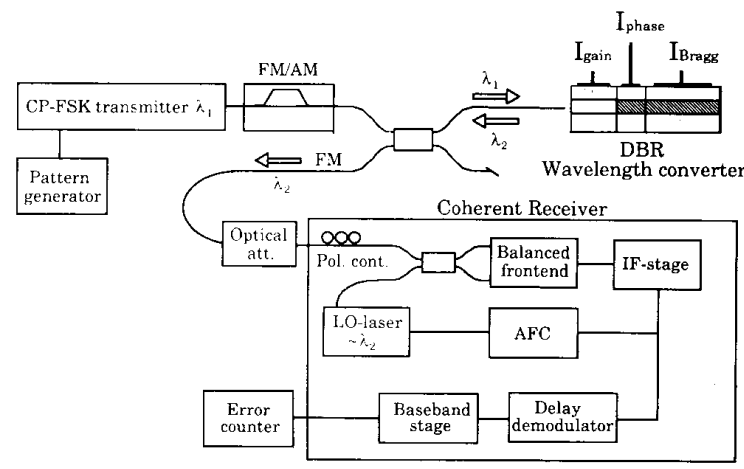

Fig. 1. Experimental setup for coherent detection of wavelength converted signals.

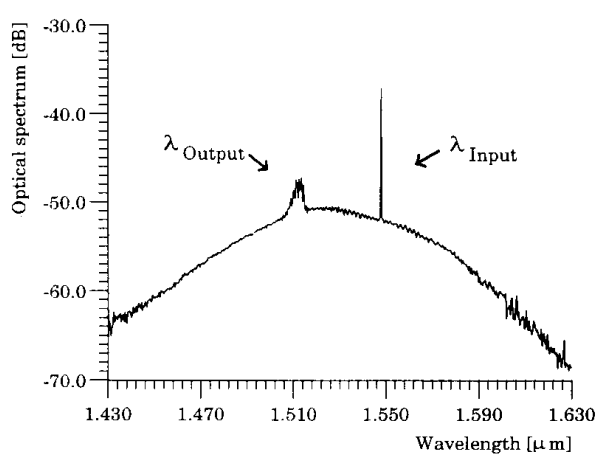

Fig. 2. Wavelength conversion range. Optical spectrum at DBR laser threshold as well as the wavelength of the remote signal laser.

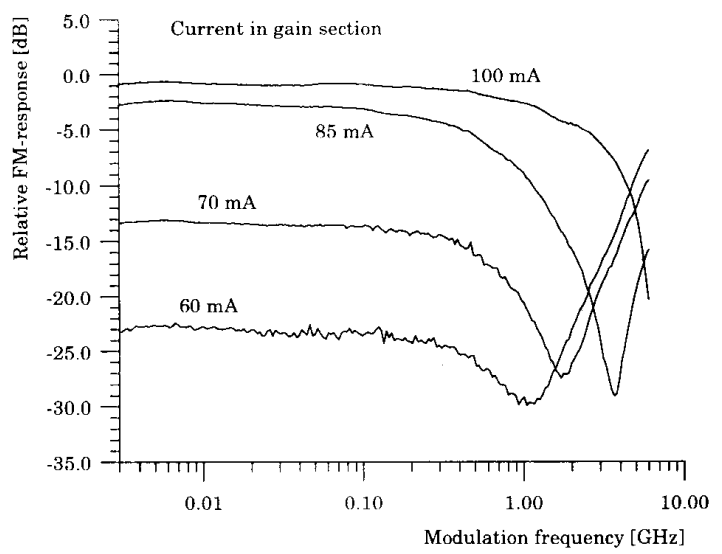

Fig. 3. Relative FM response, measured by optical modulation of the DBR laser. Current in gain section is a parameter.

of $m=1$. This is achieved with an estimated coupled power of $-1 \mathrm{dBm}$ into the converter. The corresponding IF spectrum for a modulation speed of $4 \mathrm{~Gb} / \mathrm{s}(m=0.8)$ and $5 \mathrm{~Gb} / \mathrm{s}(m=0.64)$ are shown in Fig. 4(b) and (c), respectively.

As a reference, a CPFSK experiment without wavelength conversion is conducted using two three-electrode

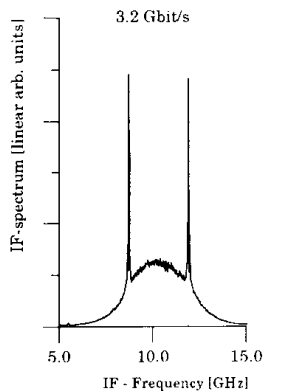

(a)

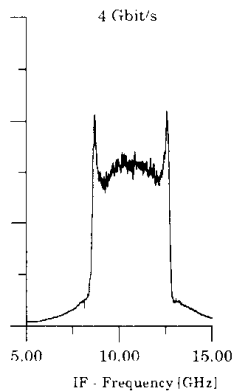

(b)

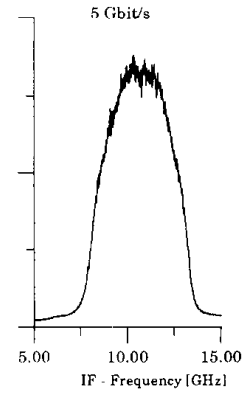

(c)
Fig. 4. Measured IF spectra for a modulation speed of: (a) $3.2 \mathrm{~Gb} / \mathrm{s}$ ( $m=1)$; (b) $4 \mathrm{~Gb} / \mathrm{s}(m=0.8)$; and (c) $5 \mathrm{~Gb} / \mathrm{s}(m=0.64)$.

$\lambda / 4$ MQW DFB lasers, similar to the remote signal laser, as a directly modulated transmitter and local oscillator. The transmitter exhibits a flat FM response and a modulation bandwidth in excess of $5 \mathrm{GHz}$. The system linewidth with these lasers is $7 \mathrm{MHz}$, and the total photocurrent generated by the LO laser is $2 \mathrm{~mA}$.

\section{RESULTS}

BER measurements are done with wavelength converted signals at 4 and $4.8 \mathrm{~Gb} / \mathrm{s}$. For comparison, BER is also measured without wavelength conversion at $4 \mathrm{~GB} / \mathrm{s}$ and $5 \mathrm{~Gb} / \mathrm{s}$, using the two three-electrode DFB lasers and the same heterodyne receiver.

It is not possible to detect wavelength converted signals at higher bit rates than $4.8 \mathrm{~Gb} / \mathrm{s}$, apparently due to a combination of IF-signal jitter and FM bandwidth limitation of the wavelength converter (Fig. 3).

Experimental data are shown in Figs. 5 and 6, together with theoretical curves, using a CPFSK system simulation program, which takes shot noise, residual relative-intensity noise, equivalent input noise in the front end, phase noise, and tight IF filtering into account [4]. The measured and calculated sensitivities for a word length of $2^{7}-1$ are shown in Table I.

The sensitivities of the wavelength converted signals are the highest reported at these bit rates. Also, the $5 \mathrm{~Gb} / \mathrm{s}$ CPFSK result without wavelength conversion is the best reported. The difference in theoretical sensitivities, with and without conversion, is due to different LO photocurrent and phase noise values.

The BER curves of the wavelength converted signal at $4.8 \mathrm{~Gb} / \mathrm{s}$ are slightly degraded compared to $4 \mathrm{~Gb} / \mathrm{s}$, due to limited bandwidth of the wavelength converter and frequency jitter in combination with the "tight" IF filtering.

As shown in Table I, the difference between results with and without wavelength conversion, relative to the theory, is very small - less than $1.5 \mathrm{~dB}$.

\section{CONCLUSION}

We have demonstrated that a CPFSK heterodyne receiver can be applied to detect wavelength converted 


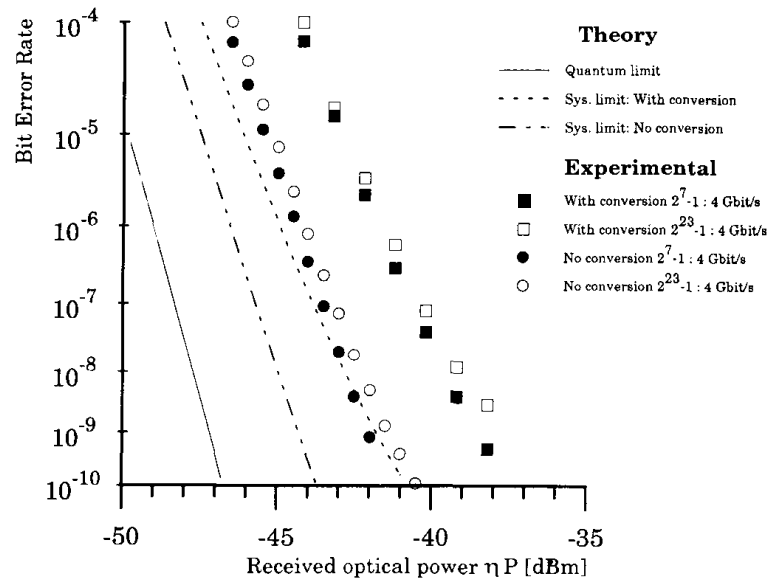

Fig. 5. Measured and calculated BER at $4 \mathrm{~Gb} / \mathrm{s}$. BER for wavelength converted signals are indicated with squares; circles represent nonwavelength-converted signals.

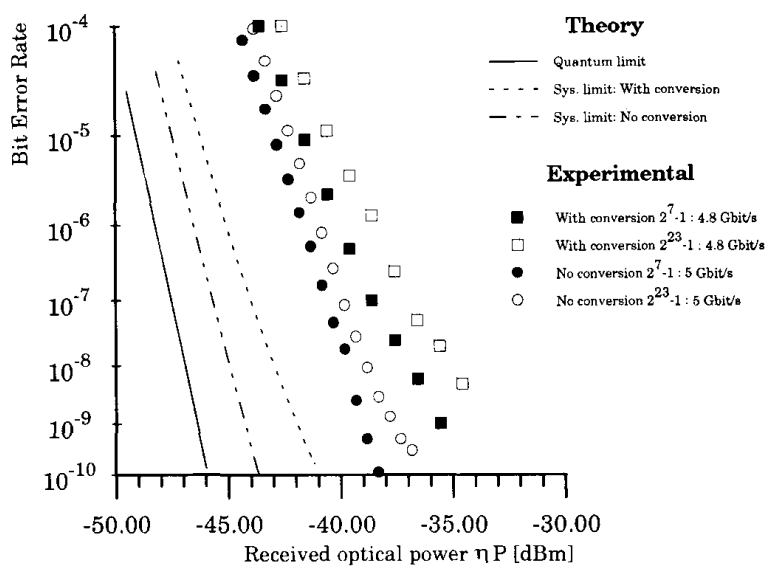

Fig. 6. Measured and calculated BER. BER for wavelength converted signals at $4.8 \mathrm{~Gb} / \mathrm{s}$ are indicated with squares; circles represent nonwavelength-converted signals at $5 \mathrm{~Gb} / \mathrm{s}$.

signals, using a DBR laser as wavelength converter. The conversion is done over a range of $35 \mathrm{~nm}$. We achieve a sensitivity of -38.7 and $-35.6 \mathrm{dBm}$ for 4 and $4.8 \mathrm{~Gb} / \mathrm{s}$, respectively. These are the highest bit rates reported to
TABLE I

Measured and Calculated Sensitivities of the Heterodyne CP-FSK RECEIVER

\begin{tabular}{lcc|cc}
\hline $\begin{array}{l}\text { Bit rate [Gb/s] } \\
\text { Wavelength }\end{array}$ & 4 & 4 & 4.8 & 5 \\
$\quad$ conversion & Yes & No & Yes & No \\
$\eta P_{s}$ experiment & $-38.7 \mathrm{dBm}$ & $-42.2 \mathrm{dBm}$ & $-35.6 \mathrm{dBm}$ & $-39.1 \mathrm{dBm}$ \\
$\eta P_{s}$ theory & $-41.8 \mathrm{dBm}$ & $-44.2 \mathrm{dBm}$ & $-42.0 \mathrm{dBm}$ & $-44.2 \mathrm{dBm}$ \\
$\Delta P$ & $-3.1 \mathrm{~dB}$ & $-2 \mathrm{~dB}$ & $-6.4 \mathrm{~dB}$ & $-5.1 \mathrm{~dB}$ \\
Difference & \multicolumn{2}{c|}{$1.1 \mathrm{~dB}$} & \multicolumn{2}{c}{$1.3 \mathrm{~dB}$} \\
\hline
\end{tabular}

date for wavelength conversion and the best sensitivities using wavelength conversion. Comparison between results with and without wavelength conversion, relative to the theory, shows a difference of less than $1.5 \mathrm{~dB}$.

\section{ACKNOWLEDGMENT}

The authors would like to thank P. Jeppesen and K. E. Stubkjaer for useful discussions. Fujitsu Laboratories Ltd. are gratefully acknowledged for supplying the DFB lasers. They thank G. Jacobsen, TFL, for the use of the CPFSK system simulation program.

\section{REFERENCES}

[1] P. Meissner, "Coherent multichannel communication systems," in Proc. 15th Optical Fiber Communication Conf. (OFC'92), San Jose, CA, 1992, paper FC1, p. 283.

[2] A. A. M. Saleh, "Optical WDM technology for networking and switching applications," in Proc. 15th Optical Fiber Communication Conf. (OFC'92), San Jose, CA, 1992, paper ThC1, p. 199.

[3] G. Grosskopf, R. Ludwig, and H. G. Weber, "140 Mbit/s DPSK transmission using all-optical frequency converter with a $4000 \mathrm{GHz}$ conversion range," Electron. Lett., vol. 24, no. 17, pp. 1106-1107, 1988.

[4] G. Jacobsen and K. Emura, "Performance of CPFSK systems with tight IF filtering and optimised delay time," in Proc. Inst. Elec. Eng., vol. 139, no. 2, pp. 158-162, 1992.

[5] R. J. S. Pedersen et al., "Tunable DBR laser for wavelength conversion of 2.5 Gbit /s signals," in Proc. 13th Int. Semiconductor Laser Conf. 92, Takamatsu, Japan, 1992, paper O-7, pp. 270-271.

[6] B. Mikkelsen et al., "Penalty free wavelength conversion of 2.5 Gbit /s signals using a tunable DBR-laser," in Proc. 18th European Conf. Optical Communication (ECOC'92), Berlin, Germany, 1992, paper We A10.4, pp. 441-444.

[7] Y. Kotaki and H. Ishikawa, "Narrow linewidth and wavelength tunable distributed feedback lasers," in Proc. 2nd Int. Conf. Indium Phosphide and Related Materials, 1990, paper, TuC.6, pp. 185-188.

[8] F. Ebskamp and R. J. S. Pedersen, "The application of a balanced 6-15 GHz low-noise tuned front-end in a 5 Gbit/s CPFSK heterodyne system," in Proc. 18th European Conf. Optical Communication (ECOC'92), Berlin, Germany, 1992, paper Tu P1.22, pp. 309-312. 